\title{
Ability of Multiplicative Models to Simulate Stomatal Resistance along Plant Growth: Application to New Guinea Impatiens Grown in a Greenhouse.
}

\author{
M. Sourgnes, C. Migeon, H. Bouhoun Ali, P.E. Bournet, P. Cannavo and E. Chantoiseau \\ Agrocampus Ouest, UP EPHor Environmental Physics and Horticulture Research Unit, \\ F-49045 Angers,
}

France.

Keywords: stomatal resistance, porometer, container, greenhouse, multiplicative model, water comfort

\begin{abstract}
In greenhouses, optimized plant crop management is crucial for environmental reasons and for maintaining the competitiveness of the horticultural sector. In particular, optimizing water consumption is of high interest but requires predictive models needing leaf stomatal resistance $R s$ estimation. Until now, most studies deduced $R s$ by inverting the energy balance equation. On contrary, the objective of the present study is to model $R s$ for leaves on the entire height of the canopy from direct measurements with a porometer. The model was first established and validated for the upper leaves and then tested for the within-canopy leaves. In this prospect, New Guinea Impatiens plants were cultivated in containers inside a greenhouse during 16 weeks under water-comfort irrigation management. Global radiation, temperature and relative humidity of the air were continuously recorded while the stomatal resistance was measured at the top and in the middle of the canopy. Two models involving global radiation and vapor pressure deficit (Jarvis multiplicative models) were tested by using two parameterization methods. The first method consisted in deducing the model parameters independently for each week. Results showed significant differences between the parameters and a generic model could not be obtained. In the second method the model parameters were obtained from a subset of experimental data. Validating the model on the remaining datasets was quite conclusive. By extrapolating the obtained model from the upper leaves to the middle canopy leaves using the Beer-Lambert law to estimate the global radiation, acceptable correlations were reached between estimated and measured Rs. Results were however not as good as those obtained for the upper leaves.
\end{abstract}

\section{INTRODUCTION}

At a time when ecological concerns are growing, a better management of water resources in the horticultural sector appears to be necessary to remain competitive. In this prospect, understanding water transfers inside the soil-plant-atmosphere continuum is essential. Plants act as pumps, withdrawing water from the soil to compensate the loss caused by transpiration. This foliar transpiration is controlled by the stomata. Therefore, predicting the state of stomata according to the weather using a modelling approach would help better understand the interactions between the plant and its environment. Nevertheless, few efficient models exist for greenhouse pot plant crops compared with the open-field conditions (Damour et al., 2010). Moreover, very few authors focus on actual measurements of stomatal resistance under such conditions (Boulard et al., 1991; Morales 
et al., 2013). In most existing publications (Baille et al., 1994; Kichah et al., 2012), the stomatal resistance is calculated by reversing the Penman-Monteith equation and not measured directly as it is in the present study.

The aim of this study is to model the stomatal resistance of New Guinea Impatiens plants from experimental data provided by a porometer. The model is based on the climate parameters on which the opening of the stomata mainly depends, namely the solar radiation and the vapour pressure air-air deficit (calculated from the temperature and relative humidity of the air inside the greenhouse). The model is then applied not only to the upper leaves but also to the leaves at mid height of the canopy.

\section{MATERIALS AND METHOD}

\section{Plant material, growing conditions and experimental treatments}

In order to establish an empirical model and test it on another independent set of experimental data, a great number of stomatal resistance values and climatic parameters had to be collected. Experiments were conducted during 16 weeks (from March $26^{\text {th }}$ to July $\left.18^{\text {th }} 2014\right)$ inside a $100 \mathrm{~m}^{2}(10 \mathrm{~m} \times 10 \mathrm{~m})$ glasshouse compartment (with shading screens) in Angers (47॰28' North, 0॰33' East and $39 \mathrm{~m}$ altitude) in north-western France. New Guinea Impatiens (Impatiens x novae-guinea 'Paradise ${ }^{\circledR}$ Orona') crop was chosen as plant model as it is very sensitive to climate variations. Morever, as mentioned by Morille (2012), it is hypostomatic (stomata can only be found on the underside of leaves) which simplifies stomatal resistance measurements. Seedlings (3-4 leaves) were potted during the last week of March in plastic pots filled in with blond Sphagnum peat. The pots were equally distributed over four metallic shelves representing a total area of $18 \mathrm{~m}^{2}$. During the experiment, the plants were spaced out to insure a normal growth (as plants which are put too close to one another tend to grow upright with longer internodes). On July $18^{\text {th }}$, the final density on each shelf was 10 plants per $\mathrm{m}^{2}$. Plants were watered by flooding the shelves with a complete nutrient solution. Irrigation was first activated once a day (at $6 \mathrm{am}$ ) but was then adapted to the summer conditions (two to three times a day, at $6 \mathrm{am}, 2 \mathrm{pm}$ and $11 \mathrm{pm})$.

\section{Data collection}

Only one of the four shelves was instrumented. The global radiation (incident and reflected) was measured with a radiometer (CNR1, Kipp\&Zonen, Delft, The Netherlands, $\left.\pm 10 \mathrm{~W} / \mathrm{m}^{2}\right)$ above the crop canopy. The temperature $\left(\mathrm{Ta}, \pm 0.1{ }^{\circ} \mathrm{C}\right)$ and relative humidity (HR, $\pm 2 \%$ ) of the air above and at mid height inside the crop were measured by sheltered ventilated Vaisala HMP45C sensors (Campbell Scientific Ltd., Antony, France). These two parameters were used to assess the air-air vapour pressure deficit. All data were recorded every 3 seconds and then averaged over 10 min periods using a data acquisition processor (CR5000, Campbell Scientific Ltd., Antony, France).

The stomatal resistance measurements were undertaken with a porometer (AP4UM-3, Delta-T Devices Ltd., Cambridge, England) during the $10^{\text {th }}, 11^{\text {th }}, 12^{\text {th }}$ and $14^{\text {th }}$ week after plantation. Measurements were repeated on five different leaves for each level inside the canopy (level 1 - top and level 2 - middle) throughout the whole day (either every 30 minutes or every hour). Repetitions were then averaged. Contrary to measurement on level 1 , level 2 was only investigated during the $10^{\text {th }}$ and $11^{\text {th }}$ weeks. 


\section{Modeling method}

Some of the previous studies on modeling stomatal resistance (Jarvis, 1976; Thorpe et al., 1980) showed that, under water-comfort, $R s$ depends mostly on the global radiation, vapour pressure deficit and air temperature. In the case of Impatiens crop, it can however be considered independent of the temperature and expressed according to Baille et al. (1994) as:

$$
R_{S}=R_{s, \min } \frac{\left(c_{1}+R_{g}\right)}{c_{2}+R_{g}} f_{2}(V P D)
$$

$R_{s, \text { min }}$ is the minimal stomatal resistance measured for a given period. Concerning the $f_{2}$ function, two expressions mentioned by Baille et al. (1994) were successively tested, leading to Eq. (2) and (3):

$$
\begin{gathered}
R_{S}=R_{s, \min } \frac{\left(c_{1}+R_{g}\right)}{c_{2}+R_{g}}\left(1+c_{3}\left(V P D-V P D_{0}\right)^{2}\right) \\
R_{S}=R_{s, \min } \frac{\left(c_{1}+R_{g}\right)}{c_{2}+R_{g}}\left(1+d_{1} \exp \left(d_{2}\left(V P D-V P D_{0}\right)\right)\right)
\end{gathered}
$$

where $V P D_{0}$ is the vapour pressure deficit for which the stomatal resistance is minimal, so it was defined at the same time as $R_{s, \min }$. Coefficients $c_{1}, c_{2}, c_{3}, d_{1}$ and $d_{2}$ were fitted to better adjust to the measured $R s$ by minimizing the sum square difference between the measured stomatal resistance $\left(R_{s, \text { mes }}\right)$ and the calculated stomatal resistance $\left(R_{s, \text { calc }}\right)$ for both Eq. $2\left(c_{1}, c_{2}\right.$ and $\left.c_{3}\right)$ and Eq. $3\left(c_{1}, c_{2}, d_{1}\right.$ and $\left.d_{2}\right)$. To do so, the GRG (Generalized Reduced Gradient) nonlinear algorithm was used for optimizing $c_{1}, c_{2}$ and $c_{3}$ in Eq. 2 or $c_{1}, c_{2}, d_{1}$ and $d_{2}$ in Eq. 3 .

\section{RESULTS AND DISCUSSION}

\section{Climate inside the greenhouse}

The climatic parameters were recorded over 16 weeks.

Fig. 1igures 1 and 2 show the corresponding graphs for the relative air humidity, temperature, global solar radiation and vapour pressure deficit (calculated with the air temperature and relative humidity) both above and inside the canopy during week 11 . During the four weeks, when $R s$ was measured $\left(10^{\text {th }}, 11^{\text {th }}, 12^{\text {th }}\right.$ and $14^{\text {th }}$ week), the climatic conditions were similar, with sun and high temperatures during the afternoon, despite partly cloudy skies throughout the day. The temperature inside the compartment was neither lower than $15^{\circ} \mathrm{C}$ nor higher than $37^{\circ} \mathrm{C}$. The relative humidity was within the range $29-98 \%$ and the global solar radiation within the range $0-130 \mathrm{~W} \mathrm{~m}^{-2}$.

\section{Evolution of stomatal resistances}

Figure 3 shows the values of stomatal resistances obtained for 2 days of week 11, during which a complete night of measurements was operated. Error bars represent the standard deviation obtained for the five repetitions of stomatal resistance measurements. Both for the upper and lower layer of the canopy, the stomatal resistance increases throughout the day from 8 am, together with the temperature. Stomata are open to capture $\mathrm{CO}_{2}$ for photosynthesis, but closed during the hottest hours of the day to reduce water loss through transpiration. Thus at 15:20 the growth of stomatal resistance accelerates until it reaches a peak at 20:10 corresponding to values of almost $2500 \mathrm{~s} \mathrm{~m}^{-1}$ (lower layer) and $1700 \mathrm{~s} \mathrm{~m}^{-1}$ (upper layer). Then the stomatal resistances decrease until the morning when the coolest temperatures are measured and the global solar radiation starts growing (Figure 2). In order to evaluate the relationship between stomatal resistances, global solar radiation and vapor pressure deficit, Figure 4 left and right were analyzed. They depict 
the daily dynamics of $R s$ showing a marked hysteresis between two periods: the morning and the early hours of the afternoon (from 06:00 to 14:00); and the late afternoon and the night (from 14:00 to 05:45). This hysteresis is more pronounced for the evolution of stomatal resistance as a function of vapor pressure deficit than as a function of global solar radiation, but can be clearly observed for the two parameters.

\section{Modeling the stomatal resistance of upper leaves}

The stomatal resistances were estimated for weeks 10, 11, 12 and 14 (Tab.1) considering first independent weekly datasets. The match between modeled and measured values for each set of weekly data both for Eq. 2 and 3 is shown using the RMSE, the slope of the linear regression obtained for $R_{s, \text { mes }}=\mathrm{f}\left(R_{s, \text { calc }}\right)$, and the linear determination coefficient $\left(\mathrm{R}^{2}\right)$. The parameterization method provides good results (with an average $\mathrm{R}^{2}$ of 0.69). The parameterization coefficients that were found for a given week were however very different from the ones found for another. A hypothesis could be the influence of the physiological stage of the plant as reported by Jones (1992). Consequently, when the modelling equation with a set of parameters obtained for a given week was applied to another week, the predicted values of $R s$ were very far from the measured ones. To get a better model, all data sets from the first three weeks $(10,11$ and

12) were used to estimate coefficients $c_{1}, c_{2}, c_{3}$ (Eq. 2) and $c_{1}, c_{2}, d_{1}, d_{2}$ (Eq. 3). The obtained values are displayed at the bottom of Tab. 1. The minimum stomatal resistance $\left(R_{S, \min }\right)$ was also fixed, choosing the lowest value of all weeks $\left(48.1 \mathrm{~s} \mathrm{~m}^{-}\right.$ ${ }^{1}$ ) and the $V P D_{0}$ associated to this value was $2.839 \mathrm{kPa}$. Finally, the obtained model was tested on another week (14) as a validation test (

Fig. 5). The linear regression $R_{s, \text { mes }}=\mathrm{f}\left(R_{s, \text { calc }}\right)$ led to $\mathrm{R}^{2}=0.756$ for Eq. 2 and 0.227 for Eq. 3 , clearly stating that Eq. 2 was actually the best model.

\section{Application of the model to the mid-height leaf stomatal resistance}

In order to assess the robustness of the model, it was then applied to the leaves located at mid height inside the canopy. The global solar radiation inside the canopy required in Eq. 2 was first calculated using the Beer's law (exponential decay): $R_{g(z)}=$ $R_{g\left(z_{0}\right)} \exp \left(-k L A I^{z} / z_{0}\right)$ where $\operatorname{Rg}(z)$ is the global radiation at a depth $z$ inside the crop, $\operatorname{Rg}\left(z_{0}\right)$ is the global radiation at the top of the crop, $k$ is the extinction coefficient and $z_{0}$ is the height of the crop. An extinction coefficient $k=1.15$ was used corresponding to the value found by Morille et al. (2013) for Impatiens. The lower-layer was considered in the middle of the crop: $z / z_{0}=1 / 2$ and the LAI was measured each week. The vapor pressure deficit inside the canopy was calculated using the air temperature and the relative humidity that were given by sensors inside the canopy at the lower layer. Then the model was tested on the data sets of weeks 10 and 11 separately. Results are shown in 

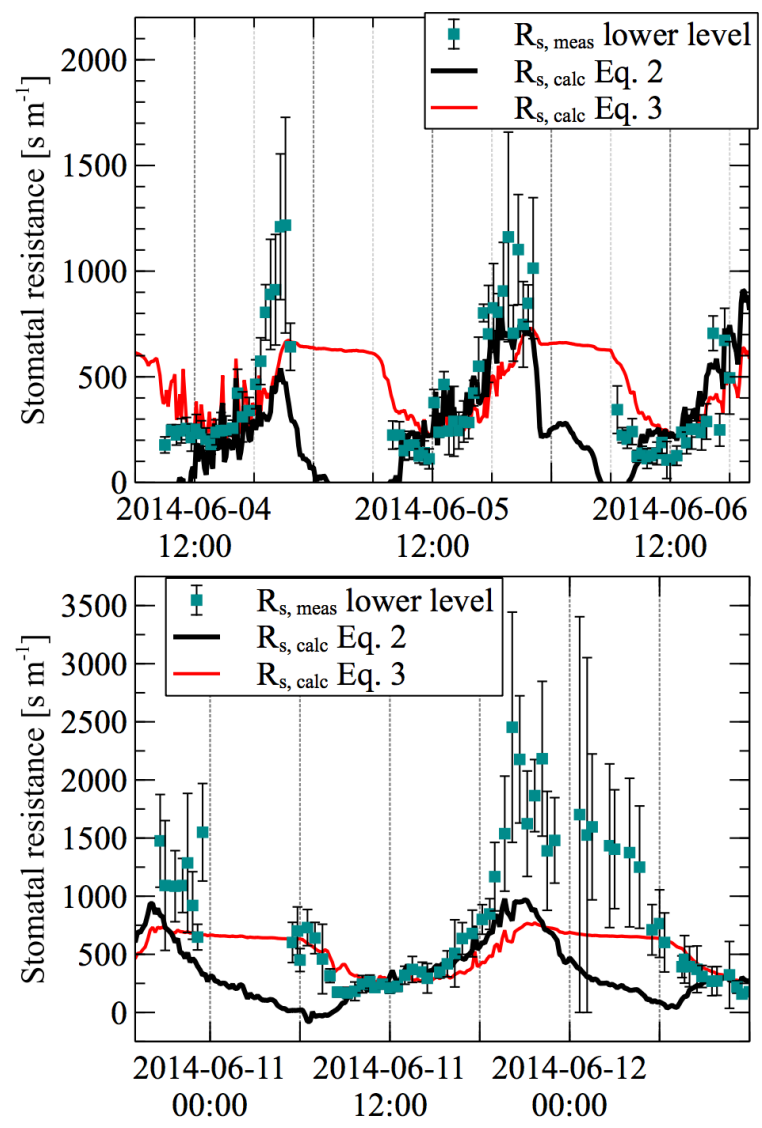

Fig. 6. The errors bars (representing the standard deviation obtained for the five repetitions of stomatal resistance measurements) are bigger than for the upper-layer measurements and the model seems less adapted to this layer than to the upper one. In fact for weeks 10 and 11, Eq. 3 provides better results than Eq. 2 with $\mathrm{R}^{2}=0.538$ (week 10) and 0.658 (week 11), while Eq. 2 leads respectively to $\mathrm{R}^{2}=0.507$ and 0.395 . Moreover, the "night peak" was also less well modeled than for the upper-layer by Eq. 2, and negative values of stomatal resistance could be obtained, showing that the model was not relevant for this layer.

Consequently none of the two tested models seems to be optimal to predict the stomatal resistance of the upper (Figure 5) or mid-height (Figure 6) leaves. First, it was reported that during the night, as the global solar radiation was zero, in both equations the stomatal resistance became only a function of the vapor pressure deficit, which seems not to be appropriate to correctly predict the observed "night peak" (Figure 2). Second, an explanation of the discrepancies of the model during daytime could be the daily hysteresis loop that was evidenced (Figure 4). This hysteresis was already observed by Prenger et al. (2002) and Medrano et al. (2005) and could explain why the multiplicative models that do not take this phenomenon into account are not ideal to estimate properly the stomatal resistance, despite their common use. As explained by Tuzet et al. (2003), hysteresis arises because of the dependence of the stomatal resistance on multiple environmental and physiological factors (light, temperature, humidity, intercellular $\mathrm{CO}_{2}$ concentration) which are not all considered in the present study.

\section{CONCLUSION}


The aim of this study was to model the stomatal resistance using experimental measurements from a porometer while most studies use an inversion method from evapotranspiration measurements. Two multiplicative models were tested considering two methods. In the first method, parameters of the models were established for 4 independent weeks, leading to a strong variability of the coefficients. In the second method, the parameters were assessed from data collected on 3 weeks. Pretty good results were obtained when applying the corresponding model to a fourth week. However, some discrepancies were observed at night, when models assume that $R s$ only depends on the VPD. The present study also concludes that multiplicative models are perhaps not the best way to model stomatal resistance. Practically, they could be improved by taking into account other parameters and phenomenon, like hysteresis between $R s$ and $V P D$, or $R s$ and $R g$.

\section{Literature cited}

Baille, M., Baille, A., Laury, J.C., 1994. Canopy surface resistances to water vapour transfer for nine greenhouse pot plant crops. Scientia Hort. 57, 143-155.

Boulard, T., Baille, A., Mermier, M., Vilette, F., 1991. Mesures et modélisation de la résistance stomatique foliaire et de la transpiration d'un couvert de tomate de serre. Agron. 11, 259-274.

Damour, G., Simonneau, T., Cochard, H., Urban, L., 2010. An overview of models of stomatal conductance at the leaf level. Plant Cell Environ. 33, 1419-1438.

Jarvis, P. G. (1976). The interpretation of the variation in leaf water potential and stomatal conductance found in canopies in the field. Philosophical Transactions of the Royal Society, London, Series B, 593-610.

Jones H.G. (1992) Stomata. In Plants and Microclimate:A Quantitative Approach to Environmental Plant Physiology (ed. H.G. Jones) pp. 131-162. Cambridge University Press, Cambridge,UK.

Medrano, E., Lorenzo, P., Sánchez-Guerrero, M.C., Montero, J.I., 2005. Evaluation and modelling of greenhouse cucumber-crop transpiration under high and low radiation conditions, Scientia Hort. 105, 163-175.

Morales, C. G., Pino, M. T., \& del Pozo, A. (2013). Phenological and physiological responses to drought stress and subsequent rehydration cycles in two raspberry cultivars. Scientia Horticulturae, 162, 234-241.

Morille, B., 2012. Élaboration d'un modèle du climat distribué à l'échelle de l'abri et de la plante en cultures ornementales sous serres : Analyse des transferts de masse et de chaleur, bilans énergétiques. Ph.D Thesis, Agrocampus Ouest Angers, Angers, France.

Morille, B., Migeon, C. and Bournet, P.E., 2013. Is the Penman-Monteith model adapted to predict transpiration under greenhouse conditions? Application to a New Guinea Impatiens crop. Scientia Hort. 152, 80-91.

Prenger, J. J., Fynn, R. P., Hansen, R. C., 2002. A comparison of four evapotranspiration models in a greenhouse environment. Transactions of the ASAE 45(6), 1779-1788

Thorpe, M.R., Warrit, B. and Landsberg, J.J., 1980, Responses of apple leaf stomata: a model for single leaves and a whole tree. Plant Cell Environ. 3, 23-27.

Tuzet, A., Perrier, A., Leuning, R.,2003. A coupled model of stomatal conductance, photosynthesis and transpiration. Plant Cell Environ. 26, 1097-1116.

\section{$\underline{\text { Tables }}$}


Table 1. Results of the fit for different equations and different weeks

\begin{tabular}{|c|c|c|c|c|c|c|}
\hline \multirow{2}{*}{$\begin{array}{c}\text { Week } \\
\mathrm{N}^{\circ}\end{array}$} & \multirow{2}{*}{$\begin{array}{c}R s, \min \\
{[\mathrm{s} / \mathrm{m}\rceil}\end{array}$} & \multirow{2}{*}{$\begin{array}{l}V P D_{0} \\
\lceil\mathrm{kPa}\end{array}$} & \multicolumn{2}{|c|}{ Equation 1} & \multicolumn{2}{|c|}{ Equation 2} \\
\hline & & & Coefficient & Value & Coefficients & Value \\
\hline \multirow{7}{*}{10} & \multirow{7}{*}{48.1} & \multirow{7}{*}{2.839} & $c_{1}$ & 188.349 & $c_{1}$ & 56.374 \\
\hline & & & $\mathrm{c}_{2}$ & 6.506 & $\mathrm{c}_{2}$ & 5.048 \\
\hline & & & $c_{3}$ & $-0,141$ & $\mathrm{~d}_{1}$ & 1.249 \\
\hline & & & & & $\mathrm{d}_{2}$ & 0.690 \\
\hline & & & RMSE & 88.490 & RMSE & 114.853 \\
\hline & & & Slope & 1.061 & Slope & 1.081 \\
\hline & & & $\mathbf{R}^{2}$ & 0.796 & $\mathbf{R}^{2}$ & 0.655 \\
\hline \multirow{7}{*}{11} & \multirow{7}{*}{59.4} & \multirow{7}{*}{1.935} & $c_{1}$ & 223.806 & $c_{1}$ & 49.001 \\
\hline & & & $c_{2}$ & 10.694 & $c_{2}$ & 6.361 \\
\hline & & & $c_{3}$ & -0.350 & $\mathrm{~d}_{1}$ & 1.275 \\
\hline & & & & & $\mathrm{d}_{2}$ & 0.818 \\
\hline & & & RMSE & 185.844 & RMSE & 243.889 \\
\hline & & & Slope & 1.066 & Slope & 1.316 \\
\hline & & & $\mathbf{R}^{2}$ & 0.747 & $\mathbf{R}^{2}$ & 0.609 \\
\hline \multirow{7}{*}{12} & \multirow{7}{*}{49.3} & \multirow{7}{*}{2.125} & $c_{1}$ & 371.739 & $c_{1}$ & 97.708 \\
\hline & & & $c_{2}$ & 7.842 & $c_{2}$ & 4.793 \\
\hline & & & $c_{3}$ & -0.372 & $d_{1}$ & 1.748 \\
\hline & & & & & $\mathrm{d}_{2}$ & 1,297 \\
\hline & & & RMSE & 172.386 & RMSE & 209.525 \\
\hline & & & Slope & 1.150 & Slope & 1.310 \\
\hline & & & $\mathbf{R}^{2}$ & 0.736 & $\mathbf{R}^{2}$ & 0.640 \\
\hline \multirow{7}{*}{14} & \multirow{7}{*}{50.82} & \multirow{7}{*}{2.392} & $c_{1}$ & 304.050 & $c_{1}$ & 130.625 \\
\hline & & & $c_{2}$ & 5.181 & $c_{2}$ & 2.603 \\
\hline & & & $c_{3}$ & -0.178 & $\mathrm{~d}_{1}$ & 0.538 \\
\hline & & & & & $\mathrm{d}_{2}$ & 0.482 \\
\hline & & & RMSE & 203.992 & RMSE & 202.604 \\
\hline & & & Slope & 1.0288 & Slope & 1.1274 \\
\hline & & & $\mathbf{R}^{2}$ & 0.658 & $\mathbf{R}^{2}$ & 0.679 \\
\hline \multirow{7}{*}{$\begin{array}{l}10, \\
11, \\
12\end{array}$} & \multirow{7}{*}{48.1} & \multirow{7}{*}{2.839} & $c_{1}$ & 316.667 & $c_{1}$ & 73.110 \\
\hline & & & $c_{2}$ & 8.869 & $c_{2}$ & 7.264 \\
\hline & & & $c_{3}$ & -0.150 & $\mathrm{~d}_{1}$ & 2.745 \\
\hline & & & & & $\mathrm{d}_{2}$ & 0.851 \\
\hline & & & RMSE & 208.536 & RMSE & 351.956 \\
\hline & & & Slope & 1.618 & Slope & 0.629 \\
\hline & & & $\mathbf{R}^{2}$ & 0.756 & $\mathbf{R}^{2}$ & 0.227 \\
\hline
\end{tabular}

\section{Figures}
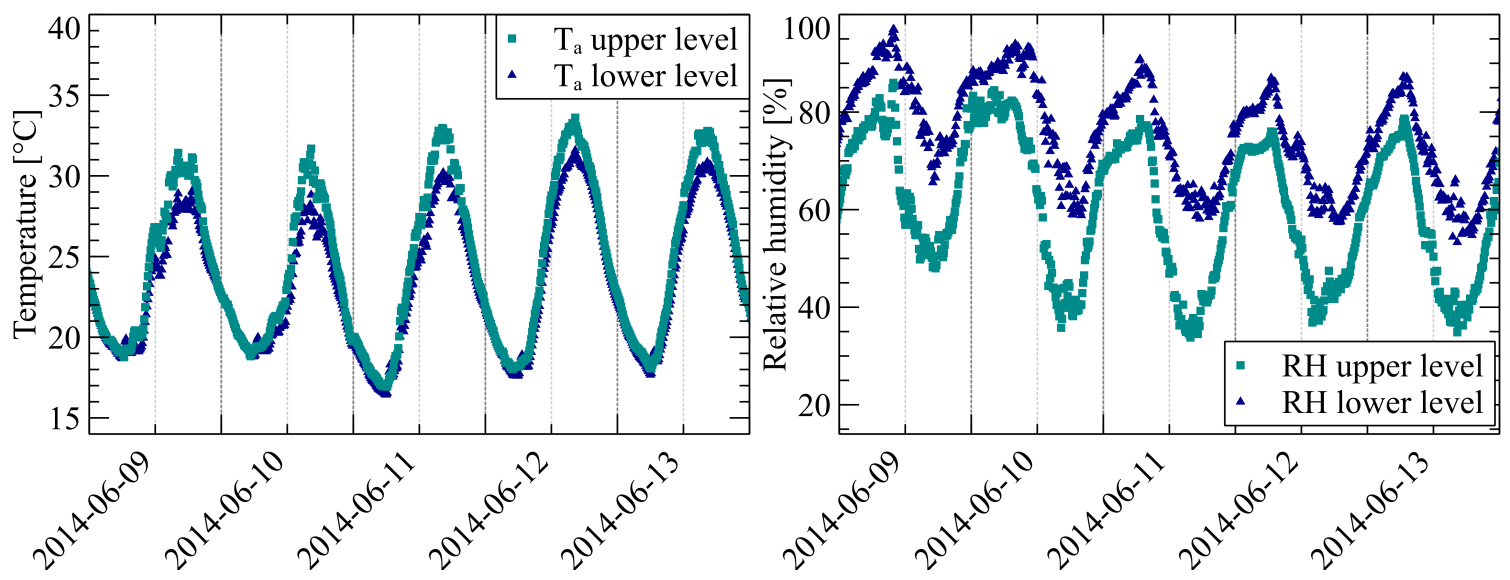
Fig. 1. Time evolution of the air temperature (left) and relative humidity (right) inside the greenhouse during week 11.

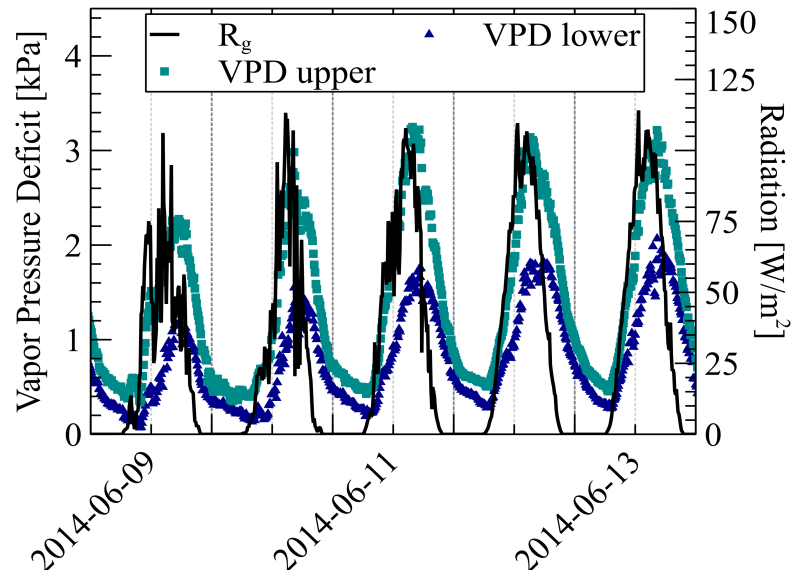

Fig. 2. Time evolution of global solar radiation and vapor pressure deficit on week 11.

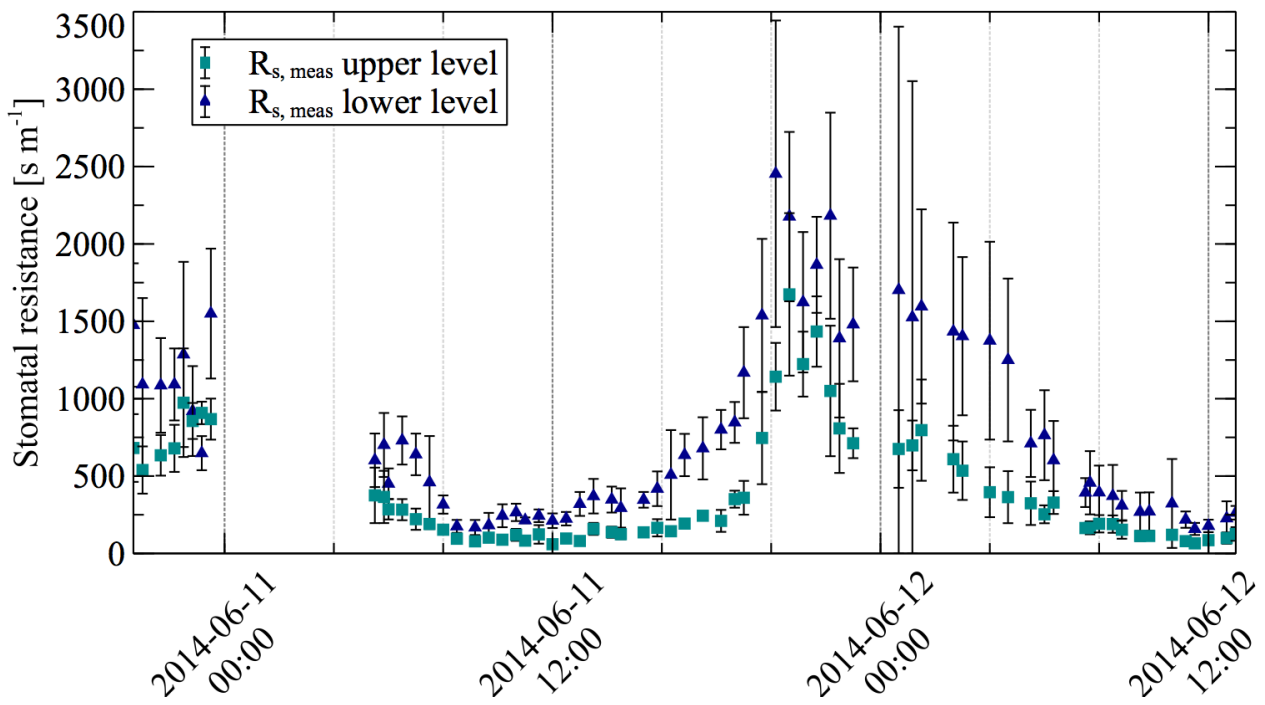

Fig. 3. Time evolution of stomatal resistances during week 11.

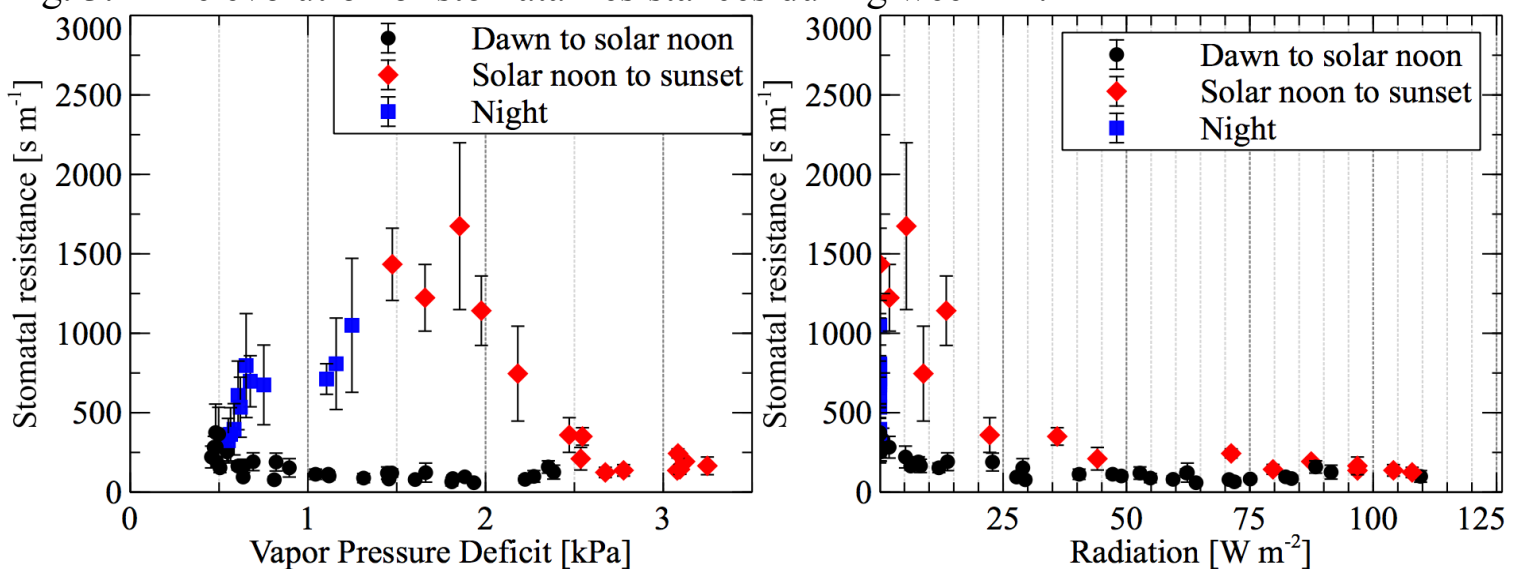


Fig. 4. Evolution of stomatal resistance in the upper canopy layer on June the $11^{\text {th }}$ and $12^{\text {th }}$ as a function of vapor pressure deficit (left), and as a function of global solar radiation (right).

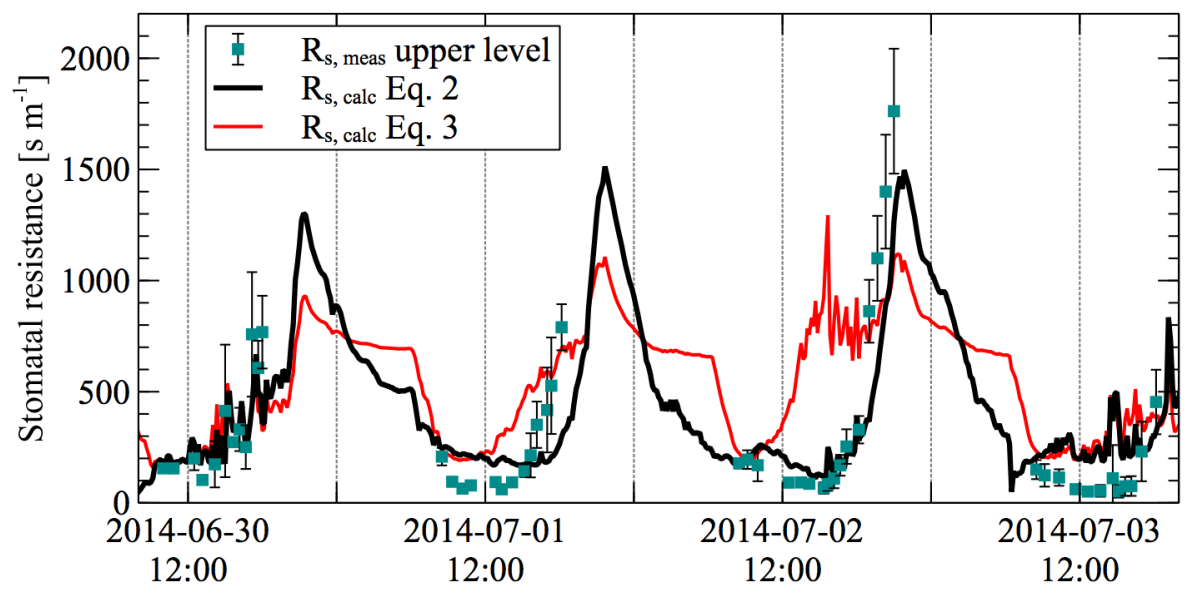

Fig. 5. Comparison between measured values of stomatal resistance during week 14 and calculated values using the model parameterized on the weeks 10, 11 and 12 .
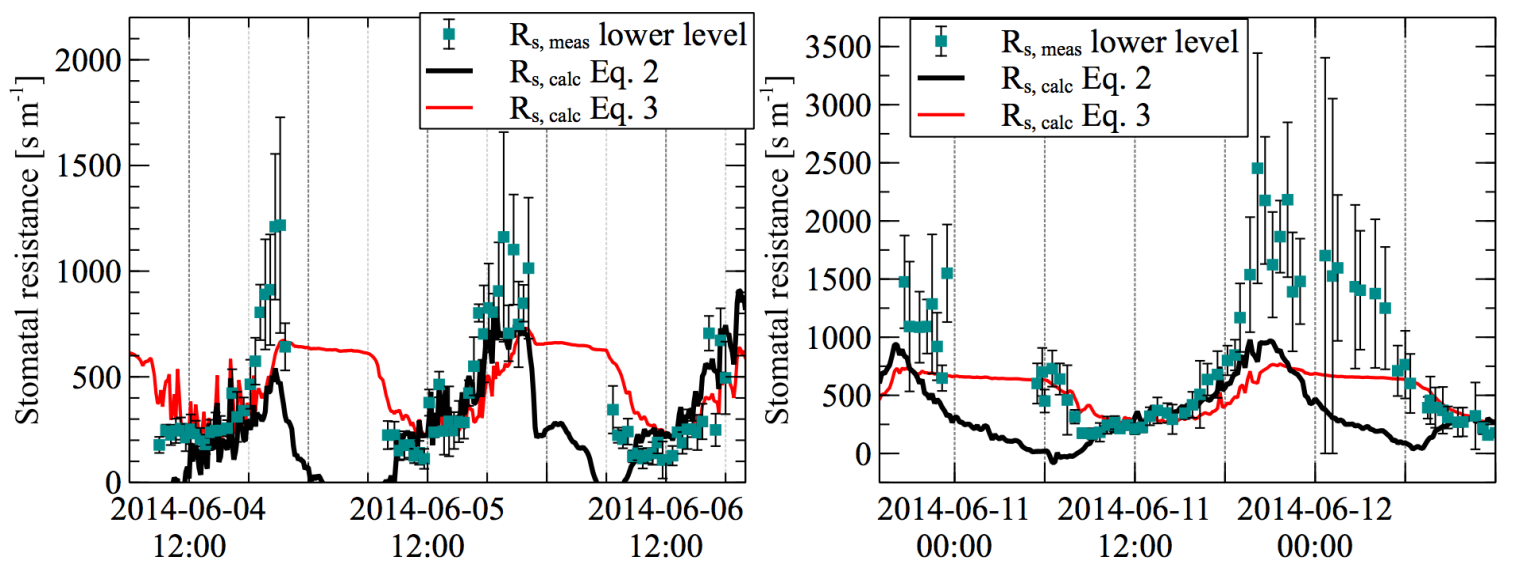

Fig. 6 Comparison between measured and simulated values of $R s$ in the lower-layer on week 10 (left) and 11 (right). 